\title{
Design and Performance Analysis of Cost-Effective and Fast Inter-Domain NEMO Scheme with Multicasting Support
}

\author{
Sunghee $\mathrm{Han}^{+} \cdot$ Jongpil Jeong ${ }^{++}$
}

\begin{abstract}
In recent years, there are many data and multimedia services that are supported by WiFi-enabled mobile devices. As a result, the demand for the ability to connect to the Internet anywhere is rapidly increasing and network infrastructure is becoming increasingly important. The design of cost-efficient network mobility (NEMO) protocol is intended to reduce the demand for limited wired / wireless network bandwidth at the signaling of mobility support and packet delivery operations. In this paper, we propose a cost-effective inter-LMA domain mobility management scheme which provides fast handover with multicasting support in NEMO environments. And our Fast PR-NEMO scheme is compared with N-PMIPv6, rNEMO, and PR-NEMO. In conclusion, our proposed scheme shows the best performance in terms of location updating cost, and packet tunneling cost.
\end{abstract}

Keywords : Multicasting, Handover, NEMO, Inter-Domain, PMIPv6, Cost Effcetive

\section{멀티캐스팅 지원의 비용효과적인 도메인간 빠른 $\mathrm{NEMO}$ 기법의 설계 및 성능분석}

한 성 희 ${ }^{\dagger} \cdot$ 정 종 필 ${ }^{\dagger+}$

요 약

최근 $\mathrm{Wi}-\mathrm{Fi}$ 기능이 내장된 휴대용 장비가 제공하는 다양한 자료와 멀티미디어 서비스가 점점 늘어나고 있으며, 어디서든 인터넷에 접속하 려는 전반적인 요구가 급격히 증가하고 있다. 이에 따라 네트워크에 많은 비용 부담이 증가하고 있다. 따라서, 모바일 네트워킹에 관한 최근의 연구 중 에너지 효율적인 네트워크 이동성 기술은 큰 주목을 받고 있다. 네트워크 이동성 환경에서 비용 효율적인 프로토콜 설계는 이동성 시 그널링과 패킷 전달, 그리고 비용 효율성의 중요한 이슈 중의 하나인 유, 무선에서 제한된 네트워크 대역폭을 절약하여 불필요한 비용을 감소 시키는 것이다. 본 연구에서는 기존의 네트워크 이동성 기법에 멀티캐스팅을 지원하는 고속 핸드오버, 효율적인 도메인간 이동성 관리와 패킷 전달 메소드를 제공하는 비용 효율적인 기법을 제안한다. 본 논문에서는 위치 갱신 비용과 패킷 터널링 비용을 합한 총 비용의 관점으로 기존 의 $\mathrm{NEMO}$ 기법인 N-PMIPv6, rNEMO, PR-NEMO의 성능과 새롭게 제안하는 Fast PR-NEMO의 성능을 비교 분석하고, 제안된 기법이 기존 제안된 기법들에 비해 총 비용이 낮은 가장 에너지 효율적인 방식임을 증명한다.

키워드 : 멀티캐스팅, 핸드오버, NEMO, Inter-Domain, PMIPv6, 비용 효율성

\section{1. 서 론}

$\mathrm{NEMO(NEtwork} \mathrm{MObility)는} \mathrm{버스,} \mathrm{기차} \mathrm{등과} \mathrm{같은} \mathrm{움직}$ 이는 차량 내에서 노드 그룹을 관리하는 개념이다. 특히 Fig. 1과 같이 외부 무선 광역 엑세스 네트워크에 연결하려

\footnotetext{
※ 이 논문은 2011년도 정부(교육과학기술부)의 재원으로 한국연구재단의 기초 연구사업 지원을 받아 수행된 것임(2011-0027030).

† 준 회 원 : 성균관대학교 정보통신대학원 석사과정

+十 정 회 원 : 성균관대학교 산학협력단 산학협력중점교수

논문접수: 2012년 5월 31일

수 정 일 : 1 차 2012년 7월 26일

심사완료 : 2012년 7월 27일

* Corresponding Author : Jongpil Jeong(jpjeong@skku.edu)
}

는 중간 라우터를 통해 인터넷에 접속하는 무선 장비를 위 한 효과적인 방법을 제공한다. 최근 휴대용 $\mathrm{Wi}-\mathrm{Fi}$ 장비의 급속한 전파와 어디에서나 인터넷 접속을 하고자 하는 요구 의 증가는 $\mathrm{NEMO}$ 기술을 보다 눈에 띄게 만들었다[1]. $\mathrm{NEMO}$ 를 적용하기 위해, $\mathrm{IETF}$ (Internet Engineering Task Force)에 의해 만들어진 NEMO-BSP(NEMO Basic Support Protocol)[2]는 확장된 MIPv6(Mobile IPv6) 호스트 프로토콜 [3]로 $\mathrm{MNN}$ (Mobile Network Node)을 위한 이동성 관리를 하는 $\mathrm{MR}$ (Mobile Router)에 설치된다. NEMO-BSP는 MR을 위한 $\mathrm{HA}$ (Home Agent)를 적용하고 $\mathrm{MNN}$ 에 관한 정보를 담은 모든 패킷은 $\mathrm{MR}$ 의 $\mathrm{HA}$ 를 통해 전달되는데 이러한 과 


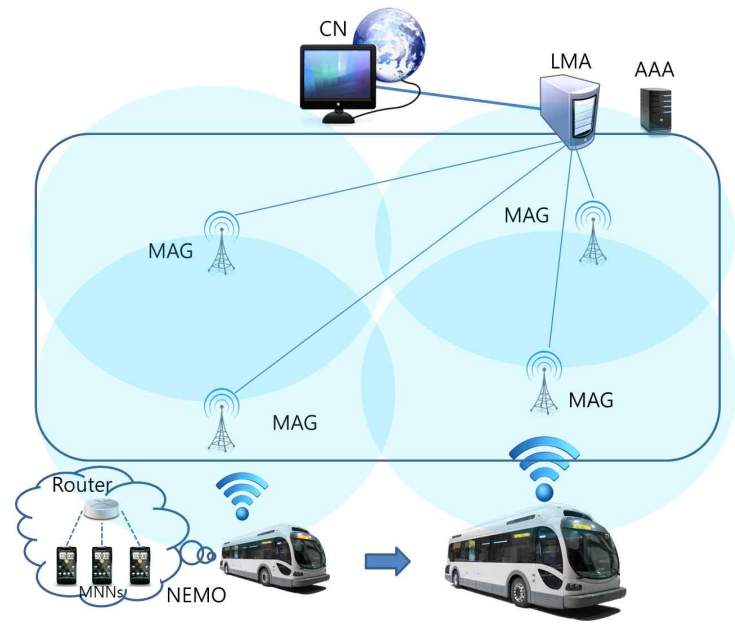

Fig. 1. Concept of the NEMO in PMIPv6

정에서 패킷 전송 오버헤드가 발생한다. 비록 $\mathrm{MNN}$ 이 다른 $\mathrm{MIPv6}$ 네트워크로부터 이동된 모바일 노드를 방문한다고 하더라도, 패킷 오버헤드는 더 발생하고 모바일 터미널은 $\mathrm{HA}$ 로 새로운 위치를 업데이트하는 것에 관여한다. 이러한 단점들은 빈번한 핸드오프와 모바일 네트워크 안의 다수의 $\mathrm{MNN}$ 을 고려할 때 비용 효율성 문제에 연결되어 있다. 모 바일 네트워킹의 몇 가지 에너지 효율적인 네트워크 연구는 라우팅 프로토콜[4], 토폴로지 제어[5], 무선 인터페이스의 전력 소비[6]와 관련하여 연구되었다. 그러나, $\mathrm{NEMO}$ 에서 이동성 시그널링과 패킷 전송으로 인한 불필요한 네트워크 대역폭을 감소시키는 비용 효율적인 프로토콜 설계는 중요 한 에너지 효율성 이슈의 하나이다[7][8][18].

최근의 연구는 PMIPv6(Proxy Mobile IPv6)를 NEMO에 적용하는 것이었다. 왜냐하면 PMIPv6[9][22]는 네트워크 기 반의 향상된 지역 이동성과 호스트 스택의 수정을 요구하지 않기 때문이다. 관련 기법으로는 N-PMIPv6(NEMOenabled PMIPv6)[10], rNEMO(relay-based NEMO)[11], PR-NEMO(Proxy Router based NEMO)[17]가 있다. $\mathrm{N}-\mathrm{PMIPv6[10]}$ 는 NEMOBSP에 정의된 $\mathrm{MR}$ 대신 $\mathrm{mMAG}$ (moving Mobile Access Gateway)를 소개한다. mMAG 또 한 $\mathrm{MNN}$ 을 위한 이동성관리를 하기 때문에 MAG(Mobile Access Gateway)는 $\mathrm{MNN}$ 의 위치 정보를 유지할 필요가 없 다. 그러나 이는 LMA(Local Mobility Anchor)가 재귀 조회 를 수행하게 하며, 패킷을 중첩된 터널을 통해 $\mathrm{MNN}$ 으로 보내게 한다. 이러한 방법은 $\mathrm{LMA}$ 의 정상 작동을 변화시키 고 심각한 패킷 터널링 비용을 발생하게 한다. $\mathrm{rNEMO}[11]$ 에서 PMIPv6 네트워크를 위한 NEMO-BSP의 간단한 지원 에 의한 패킷 터널링 비용 발생을 완화하기 위해 간단한 릴 레이 기능을 가진 스테이션이 사용되었다. 이 릴레이 스테 이션은 이동성관리 기능이 없어 $\mathrm{MAG}$ 는 $\mathrm{MNN}$ 이 언제 모바 일 네트워크가 다른 $\mathrm{MAG}$ 의 셀 지역으로 이동하든지 각각 의 $\mathrm{MNN}$ 을 위한 위치 업데이트 수행이 요구된다.

$\mathrm{PR}-\mathrm{NEMO}[17]$ 는 MR 대신 PR(Proxy Router)을 이용하 여 $\mathrm{MNN}$ 과 $\mathrm{MAG}$ 사이의 데이터 패킷과 $\mathrm{MNN}$ 대신에 $\mathrm{MAG}$
에서 노드 정보의 프록시 포워딩을 하기 위해 사용한다. $\mathrm{LMA}$ 는 하나의 모바일 네트워크안의 $\mathrm{PR}$ 과 $\mathrm{MNN}$ 을 고유한 PRGID(Proxy Router Group ID)로 관리하며 PR이 새로운 MAG로 핸드오버할 때, LMA는 모바일 네트워크 안에서 모 든 노드의 MAG IP 주소를 새로운 IP 주소로 변경하여 추 가적인 시그널링없이 $\mathrm{PR}$ 에 알려주어 비용 효율적인 핸드오 버 관리를 한다.

그러나 세가지 방법 모두 보편화된 멀티태스킹에 적합하 지 않고 이동하면서 이용하기에는 핸드오버 시간 지연이 길 어 데이터 유실이 크다. 또한 지역간 이동에 따른 도메인간 핸드오버[19][20]가 고려되지 않았다. 따라서 PMIPv6 네트 워크[21]에서 기존의 세가지 방식의 단점을 개선한 비용 효 율적인 고속 $\mathrm{NEMO}$ 프로토콜을 제안한다. 고속 $\mathrm{PR}-\mathrm{NEMO}$ 기법은 기존의 비용 효율적인 기법인 $\mathrm{PR}-\mathrm{NEMO}$ 를 기반으 로 하여 핸드오버의 경우 사전접속을 하기 위한 메시지인 Pre-PBU 메시지를 이용하여 접속 단절이 이루어 지기 전에 이동하고자 하는 MAG로 사전 연결을 하도록 한다. 그리고 사전 연결을 통해 기존의 MAG로 보내는 멀티캐스팅 트래 픽을 이동할 $\mathrm{MAG}$ 로 버퍼링을 한다. 새로운 $\mathrm{MAG}$ 로 접속이 이루어지면, 즉시 버퍼링하고 있었던 멀티캐스팅 트래픽을 $\mathrm{PR}$ 로 전달하고 $\mathrm{PR}$ 은 $\mathrm{MNN}$ 으로 전송하게 된다. 이러한 과 정을 거치게 되면 접속이 단절되고 새로운 접속이 이루어지 기 전까지 데이터 유실이 발생하는 것을 방지할 수 있고, 사전 접속을 하기 때문에 핸드오버 지연시간 또한 감소한 다. 기존의 방법과 제안된 방법의 성능 평가를 위해 위치 업데이트 비용과 패킷 터널링 비용의 전체 합을 분석하였 다. 그 결과 고속 $\mathrm{PR}-\mathrm{NEMO}$ 가 가장 비용 효과적인 방법으 로 증명되었다.

논문은 다음과 같이 구성되어 있다. 2장에서는 관련 연구 를 설명하고, 3 장은 제안하는 기법의 아키텍처와 작동절차를 설명한다. 4장에서는 제안 기법의 성능평가를 수행하고, 마지 막으로 5장에서는 성능평가 결과에 따른 결론을 내린다.

\section{2. 관련 연구}

\section{$2.1 \mathrm{~N}-\mathrm{PMIPv6}$}

N-PMIPv6[10]의 주요 아이디어는 PMIPv6 도메인을 확 장하여 모바일 네트워크로 포함시켜 확장하는 것이다. $\mathrm{MAG}$ 와 같은 고정된 인프라와 $\mathrm{MR}$ 모바일 네트워크 모두 같 은 네트워크 오퍼레이터에 속한다. N-PMIPv6에서 모바일 네트워크에 접속하는 $\mathrm{MNN}$ 도 PMIPv6 도메인의 일부분이 다. N-PMIPv6 도메인은 일반적인 IP 노드를 $\mathrm{MNN}$ 이 사용 중인 $\mathrm{IPv} 6$ 를 변경하지 않고 고정된 $\mathrm{MAG}, \mathrm{MR}$ 을 이동하는 것을 가능하게 한다. 결과적으로 $\mathrm{MIPv6}$ 같은 기존의 글로 벌 IP 이동성 기법에 비해 핸드오버 시그널링 부하는 감소 하고, 핸드오버 시 접속 지연 등의 성능은 향상된다. $\mathrm{N}-\mathrm{PMIPv6}$ 에서는 $\mathrm{MNN}$ 의 이동성 관리 기능을 $\mathrm{MR}$ 에 요구 하지 않는 반면에 $\mathrm{NEMO} \mathrm{BSP}$ 는 $\mathrm{MR}$ 이 스스로 이동성 관 리를 하는 것을 요구한다. 이것은 N-PMIPv6내의 MR과 


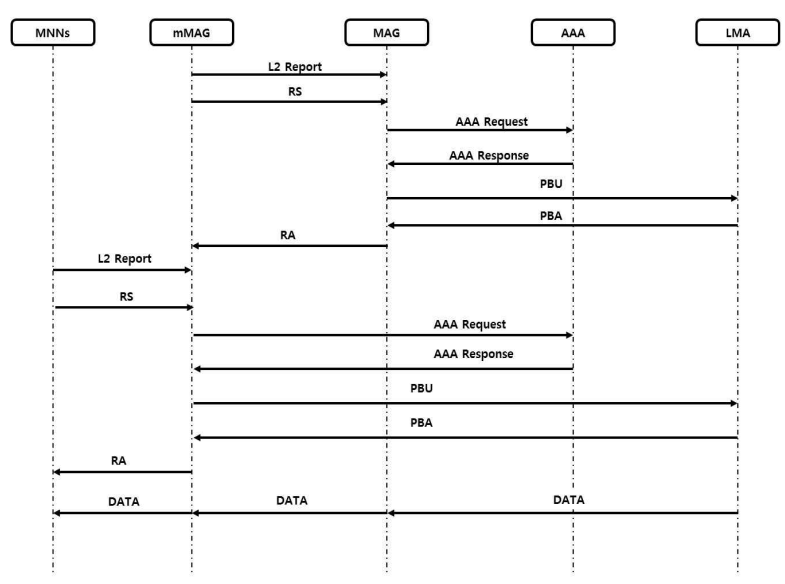

Fig. 2. Attachment operation in the N-PMIPv6

$\mathrm{MNN}$ 의 이동성을 네트워크 기반으로 관리해 주기 때문이 다. $\mathrm{N}-\mathrm{PMIPv6}$ 에서 $\mathrm{MNN}$ 은 추가적인 기능이 필요하지 않 다. IPv6 주소를 변경하는 것이 필요하지 않은 모바일 네트 워크에 접속하는 $\mathrm{MNN}$ 때문에 $\mathrm{MR}$ 은 모바일 네트워크를 위 한 확장 PMIPv6 도메인 기능이 필요하다. 그러므로 $\mathrm{N}-\mathrm{PMIPv6}$ 내 MR은 모바일을 지원하기 위해 PMIPv6의 $\mathrm{MAG}$ 와 비슷한 기능을 수행하는, $\mathrm{mMAG(moving} \mathrm{MAG)라}$ 는 $\mathrm{MR}$ 을 소개한다. $\mathrm{mMAG}$ 는 도메인에 접속한 $\mathrm{MNN}$ 와 $\mathrm{LMA}$ 에 의해 전송된 패킷에 부여된 IPv6 프리픽스에 의해 $\mathrm{PMIPv6}$ 도메인을 확장한다. $\mathrm{mMAG}$ 의 기본 작동 절차는 Fig. 2와 같으며, 다음 설명과 같은 절차로 작동한다. $\mathrm{mMAG}$ 가 고정된 $\mathrm{MAG}$ 에 접속했을 때, $\mathrm{MAG}$ 는 $\mathrm{LMA}$ 에게 $\mathrm{mMAG}$ 의 식별자를 포함한 $\mathrm{PBU}$ 메시지를 보내 접속을 알 린다. LMA는 mMAG를 식별할 IPv6 Prefix를 부여하고, 접 속된 $\mathrm{mMAG}$ 의 식별자인 $\mathrm{IPv} 6$ 프리픽스와 고정된 $\mathrm{MAG}$ 를 조합하여 $\mathrm{BCE}$ (Binding Cache Entry)를 생성한다. mMAG가 다른 $\mathrm{MAG}$ 로 이동하게 되면, $\mathrm{LMA}$ 는 새로운 $\mathrm{MAG}$ 의 정보 를 업데이트한다. 이것은 일반적인 $\mathrm{MNN}$ 이 PMIPv6의 $\mathrm{MAG}$ 에 접속했을 때와 같은 기본적인 $\mathrm{PMIPv6}$ 절차이다. $\mathrm{N}-\mathrm{PMIPv} 6$ 는 mMAG의 이동성을 $\mathrm{PMIPv6}$ 가 $\mathrm{MNN}$ 을 관리 하는 것과 같은 방법으로 관리한다. $\mathrm{mMAG}$ 에 접속하는 $\mathrm{MNN}$ 의 관점으로 보면 $\mathrm{mMAG}$ 는 $\mathrm{N}-\mathrm{PMIPv} 6$ 도메인에서 고정된 $\mathrm{MAG}$ 와 같이 동작한다. 특별히 $\mathrm{MNN}$ 이 $\mathrm{mMAG}$ 에 접속할 때, PMIPv6 절차에 따라 mMAG는 LMA에 이를 알 리고 $\mathrm{MNN}$ 을 위한 IPv6 프리픽스를 얻는다. $\mathrm{LMA}$ 는 전달받 은 프리픽스 인 $\mathrm{MNN}$ 의 $\mathrm{ID}$ 와 $\mathrm{MAG}$ 의 $\mathrm{IPv} 6$ 주소로 조합된 새로운 $\mathrm{BCE}$ 를 추가한다. $\mathrm{LMA}$ 는 허가된 $\mathrm{MAG}$ 에게만 이러 한 요청을 허용한다. 이것은 mMAG가 N-PMIPv6 도메인 내에서 작동하기 위해서는 반드시 LMA와 보안 연결을 해 야 한다는 것을 의미한다. $\mathrm{BC}$ 의 재귀 조회를 지원하기 위해 $\mathrm{LMA}$ 기능을 확장한다. 첫 조회에서 $\mathrm{LMA}$ 는 $\mathrm{MNN}$ 이 접속 되어 있는 $\mathrm{mMAG}$ 의 정보를 얻는다. 그 후, $\mathrm{LMA}$ 는 두번째 조회에서 $\mathrm{mMAG}$ 의 $\mathrm{BC}$ 를 찾고 연계된 $\mathrm{MAG}$ 를 확인한다. 이 정보를 통해 $\mathrm{LMA}$ 는 받은 패킷을 $\mathrm{mMAG}$ 로 적절한 $\mathrm{MAG}$ 를 통해 요약할 수 있다. 그리고 $\mathrm{mMAG}$ 는 $\mathrm{MNN}$ 으로

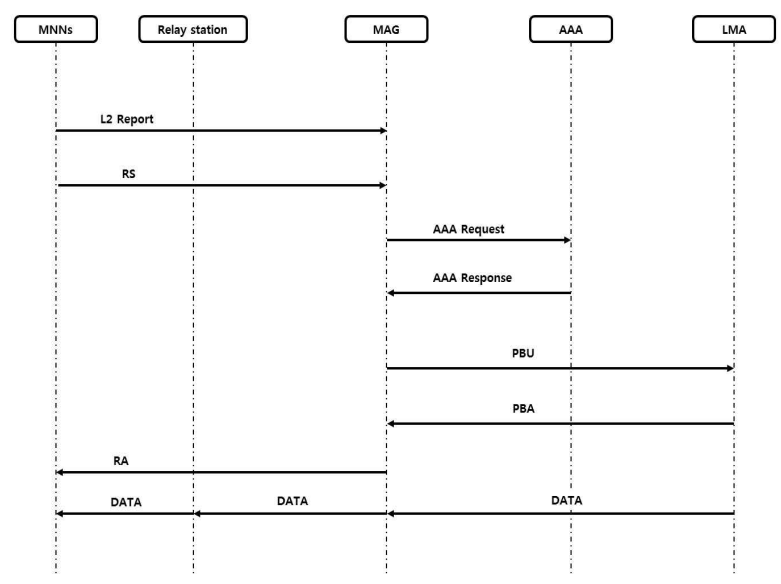

Fig. 3. Attachment operation in the rNEMO

데이터 패킷을 전송할 수 있다. 두개의 중첩된 터널은 LMA 와 $\mathrm{mMAG}$ 사이에 데이터 패킷을 요약하는데 사용된다. $\mathrm{mMAG}(\mathrm{M})$ flag라고하는 새로운 필드는 $\mathrm{LMA}$ 에 의해 $\mathrm{BC}$ 에 재귀 조회를 수행하기 위해 추가된다. $\mathrm{mMAG}$ 로 부터 전달 된 $\mathrm{PBU}$ 에 의해 생성되거나 수정된 $\mathrm{BC}$ 항목은 $\mathrm{M}$ 플래그에 'yes'로 설정되고, 반면에 고정된 $\mathrm{MAG}$ 에서 전송된 $\mathrm{PBU}$ 에 의해 생성되거나 수정된 항목은 $\mathrm{M}$ 플래그에 ' $\mathrm{no}$ '라고 설정 된다. 이 플래그는 LMA의 불필요한 재귀 조회 수행을 방지 하기 위해 사용된다.

\section{2 rNEMO}

rNEMO[11]의 릴레이 스테이션은 PMIPv6 네트워크에서 $\mathrm{NEMO}$ 를 쉽게 할 수 있도록 한다. Fig. 3과 같은 접속 절차 를 수행하며, MNN이 PMIPv6 도메인에 접속했을 때 릴레 이 스테이션을 통해 $\mathrm{MNN}$ 으로 전달된 $\mathrm{LMA}$ 의 프리픽스 정보를 이용하여 IPv6 주소를 설정한다. PMIPv6 네트워크 에서는 $\mathrm{LMA}$ 는 $\mathrm{MNN}$ 의 $\mathrm{HA}$ 역할을 하고 설정 주소는 $\mathrm{MNN}$ 의 $\mathrm{HoA}$ (Home Address)로 사용된다. $\mathrm{MNN}$ 이 다른 PMIPv6 도메인으로 이동할 때, 일종의 AR(Access Router) 인 MAG로 접속하고 인터넷 엑세스와 LMA로 부터 엔드 포인트를 제공한다. MAG와 링크 계층 연결이 만들어 지기 위해서, $\mathrm{MNN}$ 은 IEEE $802.1 x$ 와 같은 링크 엑세스 인증을 한다. 엑세스 인증이 성공적으로 이루어지면, $\mathrm{LMA}$ 는 홈 네 트워크 링크와 $\mathrm{MNN}$ 의 식별자 정보를 $\mathrm{MAG}$ 로 보낸다. $\mathrm{MAG}$ 는 $\mathrm{PBU}$ 메시지를 $\mathrm{MAG}$ 의 인터페이스를 설정한 프록 시 $\mathrm{CoA}$ 와 보내고 $\mathrm{MNN}$ 의 위치 정보를 업데이트한다. $\mathrm{LMA}$ 가 $\mathrm{PBU}$ 메시지를 받을 때, $\mathrm{LMA}$ 는 LMA와 MAG간 양방향 터널을 생성한다. 반면에 MAG는 $\mathrm{MNN}$ 프로파일에 기반하 여 RA(Router Advertisement) 메시지를 $\mathrm{MNN}$ 에 전송한다. $\mathrm{RA}$ 메시지는 $\mathrm{MNN}$ 의 홈 링크 정보가 포함되어 있기 때문 에, MNN는 홈 네트워크에 남아 HA로 어떠한 BU(Binding Update)도 하지 않는다. $\mathrm{rNEMO}$ 에서 릴레이 스테이션은 $\mathrm{MAG}$ 로부터 모든 메시지를 전달하는 간단한 장비다. 따라 서 릴레이 스테이션은 전달받은 $\mathrm{RA}$ 메시지를 $\mathrm{MNN}$ 에 보낸 
다. LMA에 패킷이 도착했을 때 LMA는 MAG로 터널을 생 성하여 패킷을 보내고, $\mathrm{MAG}$ 는 대응하는 $\mathrm{MNN}$ 에 전달받은 패킷을 보낸다. NEMO BSP에서 MNN은 PMIPv6 설계에 의해 $\mathrm{MR}$ 과의 연결을 유지하고 $\mathrm{MR}$ 은 $\mathrm{MAG}$ 로 연결한다. MNNs 대신에 MR은 BU를 PMIPv6 네트워크로 수행하며, 그렇기 때문에 $\mathrm{MNN}$ 으로의 시그널링 트래픽은 확연히 감소 한다. 그러나 NEMO BSP가 $\mathrm{HA}$ 와 터널링을 기반하고 있어 $\mathrm{MR}$ 에 추가적인 터널링 오버헤드와 처리 지연을 유발할 수 있다.

\subsection{PR-NEMO}

$\mathrm{PR}-\mathrm{NEMO}$ [17]의 기법은 PR이 PMIPv6 네트워크에 접근 할 때, $\mathrm{MAG}$ 에 의해 감지되어 $\mathrm{PBU}$ 메시지의 $\mathrm{B}$ 와 $\mathrm{N}$ 플래 그를 1 로 셋팅하여 $\mathrm{LMA}$ 에 보낸다. $\mathrm{GID}$ (Group $\mathrm{ID}$ )의 할당 을 요청하는 B 플래그는 각각의 모바일 호스트의 확장된 바 인딩 라이프타임으로 요구된 과도한 신호 비용을 감소시키 기 위한 벌크 재등록 메카니즘으로부터 유래했다[12]. 모바 일 네트워크에서 효율적인 핸드오프를 지원하기 위해 이를 이용한다. 그에 따라 새로운 $\mathrm{GID}$ 의 할당을 요청하는 $\mathrm{N}$ 플 래그를 $\mathrm{PBU}$ 메시지와 $\mathrm{PBA}$ 메시지 안에 예약된 필드가 추 가됐다. 주어진 절차를 지원하기 위해, $\mathrm{MAG}$ 는 라우터나 모 바일 호스트인 부착된 노드를 알아야 하고, 해당 정보는 $\mathrm{MAG}$ 와 $\mathrm{AAA}$ 사이의 보안 연결로부터 획득 될 수 있다. 다 른 $\mathrm{MNN}$ 이 $\mathrm{PR}$ 에 접속할 때, 그것은 $\mathrm{MNN}-\mathrm{ID}$ 를 $\mathrm{PR}$ 에 $\mathrm{RS}$ 메세지를 사용하여 보낸다. RFC 5213[9] 설계는 링크로의 노드 접속과 단절의 링크 레이어 정보 없이 운영 할 수 있 다. 정의에 따라, $\mathrm{RS}$ 메시지는 $\mathrm{MNN}-\mathrm{ID}$ 를 전송하는데 사용 된다. RS 메시지를 $\mathrm{MAG}$ 로 전송하기 위해, $\mathrm{PR}$ 은 신호와 데 이터 패킷 기능을 전달한다. $\mathrm{MNN}-\mathrm{ID}$ 는 $\mathrm{MAC}$ 주소나 $\mathrm{NAI}[13]$ 로 사용될 수 있다. NAI는 PR은 전달받은 RS를 $\mathrm{MAG}$ 로 전달하는 것이 필요하지 않기 때문에 $\mathrm{PR}-\mathrm{NEMO}$ 에 보다 적합하다. 전달하는 $\mathrm{MAG}$ 에 있는 $\mathrm{RS}$ 메시지의 출처를 구별하기 위해 $\mathrm{P}$ 플래그가 추가 되었다. RS 메시지를 받을 때, $\mathrm{MAG}$ 는 접속된 $\mathrm{MNN}$ 에 속해 있는 $\mathrm{PR}$ 을 $\mathrm{P}$ 플래그 값이 1 로 셋팅되어 있는 것으로 확인한다. $\mathrm{RS}$ 메시지에 $\mathrm{MNN}$ 의 $\mathrm{ID}$ 를 포함한다. $\mathrm{PR}$ 에 접속한 노드를 관리하기 위해, $\mathrm{PBU}$ 메시지는 $\mathrm{MAG}$ 에 보내지는데 $\mathrm{MNN}-\mathrm{ID}$ 를 포함해야 하고, 접속된 $\mathrm{PR}$ 의 $\mathrm{PR}-\mathrm{ID}$ 와 $\mathrm{B}$ 플래그를 1 로 셋텅하여 보내진다. $\mathrm{LMA}$ 는 $\mathrm{MNN}$ 를 위해 $\mathrm{HNP}$ 를 할당하고 $\mathrm{MNN}$ 과 $\mathrm{PR}-\mathrm{GID}$ 와 함께 $\mathrm{PR}$ 의 그릅을 만든다. $\mathrm{PBA}$ 메시지를 받은 다음에, $\mathrm{MAG}$ 는 $\mathrm{MNN}$ 을 $\mathrm{PR}-\mathrm{GID}$ 그룹에 추가한다. 할당된 $\mathrm{HNP}$ 는 $\mathrm{P}$ 플래그를 1로 셋팅하여 $\mathrm{RA}$ 메시지를 통해 $\mathrm{PR}$ 에 전송된다. 그리고 플래그를 0 으로 셋팅한 $\mathrm{RA}$ 메시지는 $\mathrm{MNN}$ 에 도착 한다. 효과적인 핸드오버 지원을 위해, $\mathrm{PR}$ 만이 핸드오버 운 영에 참여할 수 있다. $\mathrm{PR}$ 이 $\mathrm{nMAG}$ 로 이동 할 때, $\mathrm{pMAG}$ 는 $\mathrm{L} 2$ 시그널로 $\mathrm{PR}$ 의 접속 단절을 감지한다. 그리고 $\mathrm{PR}$ 에 등 록 해지 프로세스를 시작한다. $\mathrm{PR}$ 의 접속을 감지한 $\mathrm{nMAG}$ 는 $\mathrm{PR}$ 의 접속 초기화 과정과 같은 방법으로 위치 업데이트 과정을 수행한다. $\mathrm{AAA}$ 서비스 절차에서, $\mathrm{nMAG}$ 는 부착된

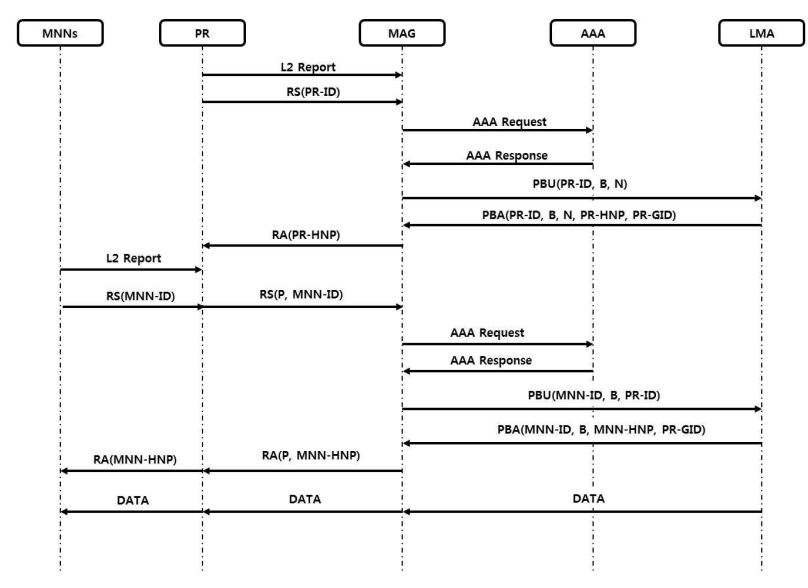

Fig. 4. Attachment operation in the PR-NEMO

노드가 NEMO 서비스를 위한 프록시 라우터인 것을 알게 된다. 그리고 $\mathrm{nMAG}$ 는 $\mathrm{B}$ 와 $\mathrm{N}$ 플래그를 담은 $\mathrm{PBU}$ 신호 메 시지를 LMA한테 보낸다. PBU 신호를 받을 때, LMA는 해 당하는 $\mathrm{PR}-\mathrm{GID}$ 와 $\mathrm{PR}-\mathrm{ID}$ 를 찾는다. $\mathrm{LMA}$ 의 $\mathrm{BCE}$ 에 $\mathrm{PR}$ 의 $\mathrm{PR}-\mathrm{ID}$ 와 $\mathrm{PR}-\mathrm{GID}$ 가 존재하면, $\mathrm{LMA}$ 는 같은 $\mathrm{PR}-\mathrm{GID}$ 를 가 지고 있는 모든 노드의 $\mathrm{MAG} \mathrm{IP}$ 주소 필드를 $\mathrm{nMAG}$ 의 $\mathrm{IP}$ 주소로 변경한다. $\mathrm{LMA}$ 는 $\mathrm{nMAG}$ 에는 $\mathrm{PR}$ 에 속해있는 $\mathrm{MNN}$ 에 관한 정보가 없기 때문에 $\mathrm{MNN}-\mathrm{ID}$ 와 $\mathrm{MNN}-\mathrm{HNP}$ 를 포 함하여 $\mathrm{PBA}$ 메시지를 N-MAG로 보내고, $\mathrm{PR}-\mathrm{HNP}$ 와 $\mathrm{PR}-\mathrm{GID}$ 도 보낸다. 정보 전달은 $\mathrm{MAG}$ 에서 데이터 패킷을 터널링 절차 없이 $\mathrm{PR}$ 에 보내는 것을 가능하게 한다. 보통 $\mathrm{PMIPv} 6$ 절차에 따라 $\mathrm{N}-\mathrm{MAG}$ 는 모든 $\mathrm{MNN}$ 의 $\mathrm{HNP}$ 와 RA 메시지를 $\mathrm{PR}$ 에 전달한다. 이 행동은 차량 안의 $\mathrm{MNN}$ 의 숫 자에 따라 PBA 메시지를 약간 크게 만든다. 그러나, 하나의 $\mathrm{MNN}$ 이 하나 또는 그 이상의 세션을 가지고 하나의 세션이 최소한 여러 패킷을 가지는 것을 고려했을 때, 증가된 $\mathrm{PBA}$ 메시지의 크기는 하나의 MNN으로부터 생성된 패킷 터널링 비용 보다 크지 않기 때문에 영향이 크다. 이와 같은 수행 절차는 Fig. 4 와 같다.

\section{3. 제안기법}

\section{1 제안 아키텍처}

본 논문에서는 앞에서 살펴본 3가지 PMIPv6 네트워크 환경에서의 NEMO 기법 중 패킷 터널링 비용과 위치 업데 이트 비용이 가장 효율적인 것으로 알려진 $\mathrm{PR}-\mathrm{NEMO}$ 를 기 반으로 하여, 멀티태스킹을 지원 하도록 하며, 핸드오버할 때 Pre-PBU 메시지를 이용하여 접속 단절이 이루어 지기 전에 이동하고자 하는 $\mathrm{MAG}$ 로 사전 연결을 하도록 한다. 사전 연결을 통해 기존의 MAG로 보내는 멀티캐스팅 트래 픽을 이동할 $\mathrm{MAG}$ 로 버퍼링을 한다. 새로운 $\mathrm{MAG}$ 로 접속이 이루어지면, 즉시 버퍼링하고 있었던 멀티캐스팅 트래픽을 $\mathrm{PR}$ 로 전달하고 $\mathrm{PR}$ 은 $\mathrm{MNN}$ 으로 전송하게 된다. 이러한 과 정을 거치게 되면 접속이 단절되고 새로운 접속이 이루어지 


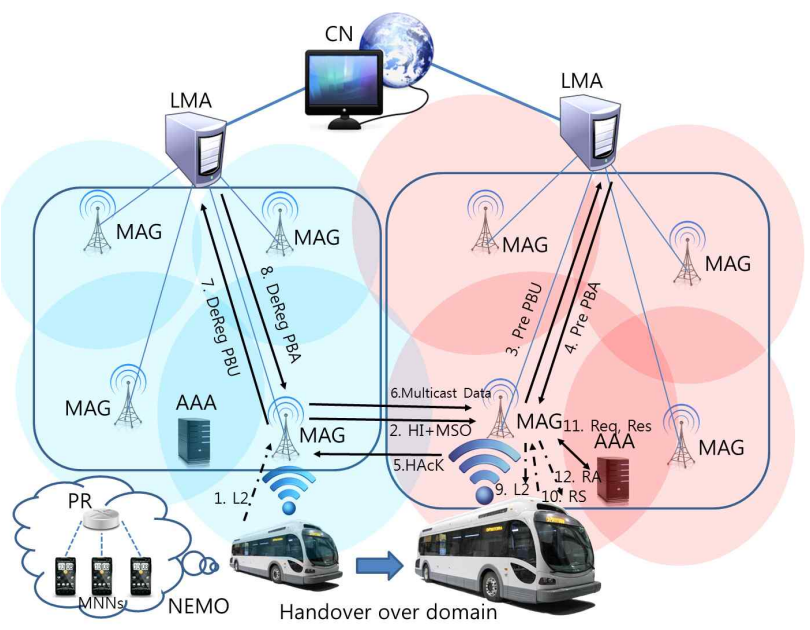

Fig. 5. Concept of the Fast PR-NEMO

기 전까지 데이터 유실이 발생하는 것을 방지할 수 있고, 사전 접속을 하기 때문에 핸드오버 지연시간 또한 감소한 다. 도메인간 핸드오버가 발생할 때에는 이전 도메인에 PR 이 접속하고 있던 $\mathrm{MAG}$ 에서 새로운 도메인의 이동이 예상 되는 $\mathrm{MAG}$ 로 $\mathrm{PR}$ 의 정보를 유선망을 이용하여 전송한다. $\mathrm{PR}$ 이 직접 접속하는 $\mathrm{MAG}$ 간 데이터 교환이 이루어 지므로 다른 경로를 이용하는 방법에 비해 물리적인 거리가 가장 가까워 접속 지연이 상대적으로 짧게 일어난다. 이러한 수 행 절차는 Fig. 5 와 같다. 본문에서는 새롭게 제안하는 기법 을 Fast $\mathrm{PR}-\mathrm{NEMO}$ 로 명명하며, 접속하고 있는 $\mathrm{MAG}$ 를 $\mathrm{pMAG}$ (previous $\mathrm{MAG}$ ), 이동하여 새로 접속할 $\mathrm{MAG}$ 를 $\mathrm{nMAG}$ (new MAG)라고 정의하고 다른 노드의 경우에도 $\mathrm{p}$, $\mathrm{n}$ 문자를 이용하여 이전, 이후 의 상태 표시를 하며, 핸드오 버 이전의 도메인은 LMA1, 핸드오버하여 이동하는 새로운 LMA는 LMA2라고 표시한다.

\section{2 작동절차}

\section{1) $\mathrm{MAG}$ 간 핸드오버 작동절차}

$\mathrm{pMAG}$ 에 접속하고 있는 $\mathrm{PR}$ 이 서비스 중 이동을 하여 $\mathrm{nMAG}$ 로 이동하려고 하면, $\mathrm{pMAG}$ 는 L2 시그널을 감지한다. $\mathrm{L} 2$ 시그널을 감지하는 것으로 접속 해제 프로세스가 시작된 다. $\mathrm{pMAG}$ 는 $\mathrm{PR}$ 의 접속이 예상되는 $\mathrm{nMAG}$ 에 핸드오버 착 수 메시지인 HI(Handover Initiate)와 멀티캐스팅 지원을 위 한 $\mathrm{MSO}$ (Multicast Support Option)를 전송한다. pMAG에게 $\mathrm{HI}, \mathrm{MSO}$ 메시지를 받은 $\mathrm{nMAG}$ 는 $\mathrm{LMA}$ 에 $\mathrm{PR}$ 을 선 접속 시키기 위한 $\mathrm{Pre}-\mathrm{PBU}$ 메시지와 $\mathrm{MSO}$ 메시지를 전송한다. Pre-PBU 메시지를 받은 $\mathrm{LMA}$ 는 $\mathrm{AAA}$ 로 $\mathrm{PR}-\mathrm{ID}$ 를 이용해 인증을 수행한다. 인증이 성공적으로 완료되면, $\mathrm{LMA}$ 는 $\mathrm{pMAG}$ 로 전송되고 있는 데이터를 $\mathrm{nMAG}$ 로 돌리지 않고 $\mathrm{nMAG}$ 로 $\mathrm{PR}$ 을 가접속 상태로 등록시킨다. $\mathrm{LMA} \mathrm{BCE}$ 에 $\mathrm{PR}$ 의 $\mathrm{PR}-\mathrm{ID}$ 와 같은 $\mathrm{PR}-\mathrm{GID}$ 를 가지고 있는 모든 노드를 새로 등록하고 가접속 상태로 설정한다. 그 후 $\mathrm{nMAG}$ 로 $\mathrm{PR}$ 의 접속이 완료되었음을 알리는 $\mathrm{Pre}-\mathrm{PBA}$ 메시지를 보낸다.

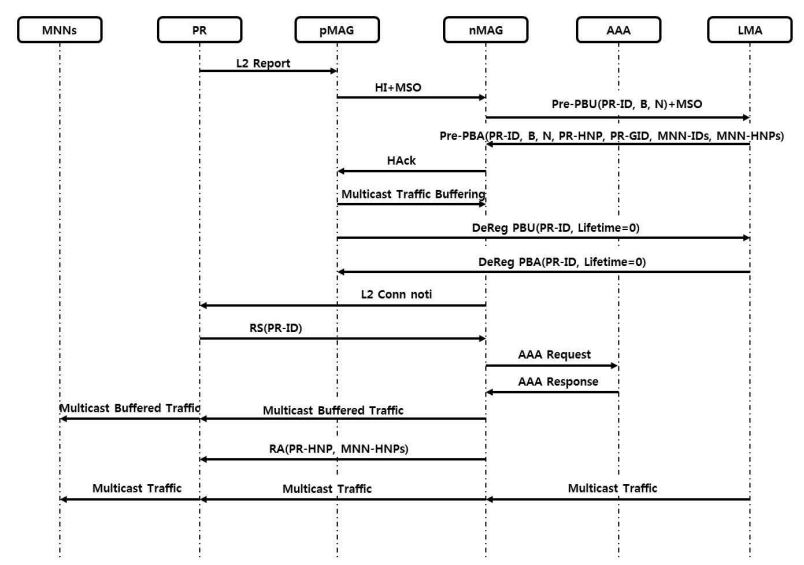

Fig. 6. Handover operation in the Fast PR-NEMO

Pre-PBA 메시지를 받은 nMAG는 핸드오버 응답 메시지인 $\mathrm{HAck}$ 를 $\mathrm{pMAG}$ 로 전송한다. HAck 메시지가 전송되면 $\mathrm{pMAG}$ 는 멀티캐스팅 트래픽을 $\mathrm{nMAG}$ 로 버퍼링한다. 그 후 $\mathrm{pMAG}$ 는 LMA로 $\mathrm{PR}$ 을 접속 해지시키기 위해 DeReg PBU 메시지를 전송한다. $\mathrm{LMA}$ 는 $\mathrm{pMAG}$ 에 접속된 $\mathrm{PR}$ 의 등록을 해지하고 $\mathrm{LMA} \mathrm{BCE}$ 에 같은 $\mathrm{PR}-\mathrm{GID}$ 를 가진 모든 데이터를 삭제하고 가접속 상태로 되어 있는 $\mathrm{nMAG}$ 의 $\mathrm{PR}-\mathrm{GID}$ 를 가 진 모든 노드의 상태를 접속 상태로 변경한다. 그리고 DeReg PBU에 대한 응답 메시지인 DeReg PBA를 pMAG 에 전송한다. 이와 동시에 $\mathrm{nMAG}$ 에서는 $\mathrm{PR}$ 에 접속이 완료 되었음을 의미하는 L2 응답 메시지를 보낸다. 메시지를 받 은 $\mathrm{PR}$ 은 접속하고자 하는 $\mathrm{nMAG}$ 에 $\mathrm{RS}$ 메시지를 전송한다. $\mathrm{nMAG}$ 는 이미 $\mathrm{PR}$ 을 등록시켜 놨기 때문에 $\mathrm{AAA}$ 서버에 정보 인증을 수행하고 인증이 되면 $\mathrm{PR}$ 에 $\mathrm{pMAG}$ 로부터 받 아두었던 멀티캐스팅 버퍼 트래픽을 전송하고 $\mathrm{PR}$ 은 해당 $\mathrm{MNN}$ 에 멀티캐스팅 트래픽을 전송한다. 버퍼링된 멀티캐스 팅 트래픽을 전송한 $\mathrm{nMAG}$ 는 접속 완료 메시지인 $\mathrm{RA}$ 를 $\mathrm{PR}$ 에 보내는 것으로 $\mathrm{MAG}$ 간 핸드오버 절차는 마무리된다. 사전 접속과 멀티캐스팅 트래픽 버퍼링으로 $\mathrm{MNNs}, \mathrm{PR}$ 입 장에서는 접속단절이 이루어지고 거의 동시에 트래픽 손실 을 최소화하여 접속 연결이 되는 것이다. Fig. 6과 같은 핸 드오버 절차를 수행한다.

\section{2) 도메인간 핸드오버 작동절차}

한 도메인내의 $\mathrm{pMAG}$ 에 접속하고 있는 $\mathrm{PR}$ 이 서비스 중 에 이동을 하여 다른 도메인 네트워크인 LMA2의 $\mathrm{nMAG}$ 로 이동하려고 하면, $\mathrm{pMAG}$ 는 $\mathrm{L} 2$ 시그널을 감지한다. $\mathrm{pMAG}$ 는 $\mathrm{PR}$ 이 접속하려고 예상되는 $\mathrm{LMA} 2$ 의 $\mathrm{nMAG}$ 에 핸드오버 착 수 메시지인 $\mathrm{HI}$ 와 멀티캐스팅 지원을 위한 $\mathrm{MSO}$ 를 전송한 다. $\mathrm{pMAG}$ 에게 $\mathrm{HI}$ 와 $\mathrm{MSO}$ 메시지를 받은 $\mathrm{nMAG}$ 는 LMA2 에 $\mathrm{PR}$ 을 미리 접속시키기 위한 $\mathrm{Pre}-\mathrm{PBU}$ 메시지와 $\mathrm{MSO}$ 메시지를 전송한다. Pre-PBU 메시지를 받은 $\mathrm{LMA} 2$ 는 $\mathrm{AAA}$ 로 $\mathrm{PR}-\mathrm{ID}$ 를 이용해 인증을 수행한다. 인증이 성공적으로 완료되면, $\mathrm{nLMA}$ 는 $\mathrm{BCE}$ 에 $\mathrm{pMAG}$ 로 부터 전달받은 $\mathrm{PR}-\mathrm{ID}$ 와 $\mathrm{PR}-\mathrm{GID}$ 를 가지고 있는 $\mathrm{MNN}$ 의 목록을 등록한다. 그 후 


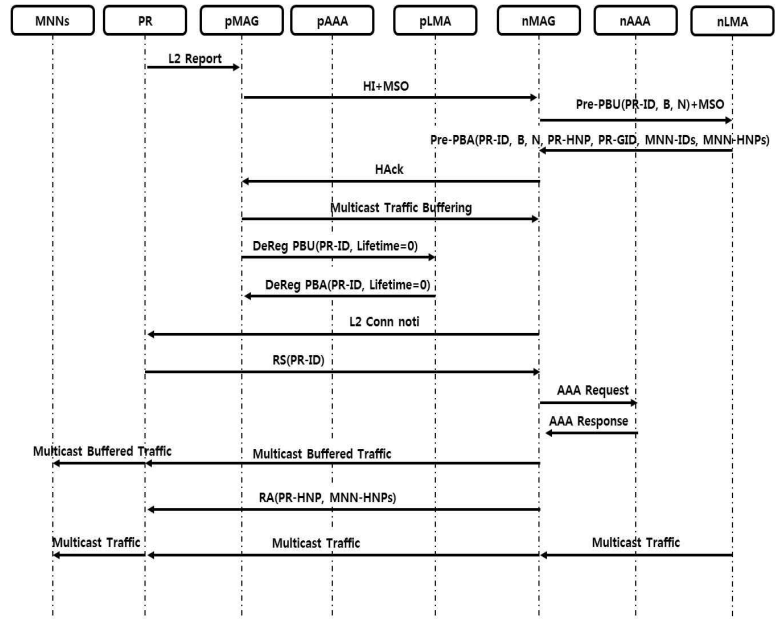

Fig. 7. Inter domain handover operation in the Fast PR-NEMO

$\mathrm{nMAG}$ 로 $\mathrm{PR}$ 의 접속이 완료되었음을 알리는 Pre-PBA 메시 지를 보낸다. Pre-PBA 메시지를 받은 $\mathrm{nMAG}$ 는 핸드오버 응답 메시지인 HAck를 pMAG로 전송한다. HAck 메시지가 전송되면 $\mathrm{pMAG}$ 는 멀티캐스팅 트래픽을 $\mathrm{nMAG}$ 로 버퍼링한 다. 그 후 $\mathrm{pMAG}$ 는 $\mathrm{LMA} 1$ 로 $\mathrm{PR}$ 을 접속 해지시키기 위해 $\mathrm{DeReg} \mathrm{PBU}$ 메시지를 전송한다. LMA1은 $\mathrm{pMAG}$ 에 접속된 $\mathrm{PR}$ 의 등록을 해지하고 $\mathrm{LMA} 1 \mathrm{BCE}$ 에 같은 $\mathrm{PR}-\mathrm{GID}$ 를 가진 모든 데이터를 삭제한다. 그리고 $\mathrm{DeReg} \mathrm{PBU}$ 에 대한 응답 메시지인 DeReg PBA를 $\mathrm{pMAG}$ 에 전송한다. 그리고 $\mathrm{nMAG}$ 에서는 $\mathrm{PR}$ 에 접속이 완료되었음을 의미하는 $\mathrm{L} 2$ 응답 메시 지를 보낸다. 메시지를 받은 $\mathrm{PR}$ 은 $\mathrm{LMA} 2$ 의 $\mathrm{nMAG}$ 에 $\mathrm{RS}$ 메시지를 전송함으로써 접속을 요청한다. $\mathrm{nMAG}$ 는 이미 $\mathrm{PR}$ 을 등록시켜 놨기 때문에 $\mathrm{nAAA}$ 서버에 정보 인증을 수행 하고 인증이 되면 $\mathrm{PR}$ 에 $\mathrm{pMAG}$ 로부터 버퍼링되어 있던 멀 티캐스팅 트래픽을 전송한다. 데이터를 받은 $\mathrm{PR}$ 은 해당 $\mathrm{MNN}$ 에 다시 전송한다. 버퍼링된 멀티캐스팅 트래픽을 전 송한 $\mathrm{nMAG}$ 는 접속 완료 메시지인 $\mathrm{RA}$ 를 $\mathrm{PR}$ 에 보내는 것 으로 $\mathrm{MAG}$ 간 핸드오버 절차는 마무리된다. 이와 같은 절차 는 Fig. 7과 같다.

\section{3) $\mathrm{MNN}$ 의 $\mathrm{MAG}$ 핸드오버 작동절차}

$\mathrm{MNN}$ 이 모바일 네트워크로부터 밖으로 이동할 때, $\mathrm{PR}$ 은 $\mathrm{L} 2$ 신호의 $\mathrm{MNN}$ 이 접속 단절을 하는 $\mathrm{L} 2$ 신호를 인식한다. $\mathrm{PR}$ 은 $\mathrm{MAG}$ 로 $\mathrm{MNN}$ 의 접속 해지를 요구하는 $\mathrm{RS}$ 메시지를 전송한다. 이 $\mathrm{RS}$ 메시지는 $\mathrm{P}$ 플래그와 $\mathrm{D}$ 플래그를 1 로 셋팅 하고, $\mathrm{MNN}-\mathrm{ID}$ 를 포함한다. $\mathrm{D}$ 플래그는 $\mathrm{MAG}$ 에게 $\mathrm{MNN}$ 의 이동을 알리기 위한 의미로 사용된다. MAG는 RS 메시지를 받으면 LMA에 Pre-PBU 메시지를 $\mathrm{MSO}$ 메시지와 전송한 다. $\mathrm{LMA}$ 는 $\mathrm{BCE}$ 에 $\mathrm{MNN}$ 을 $\mathrm{MAG}$ 에 속하는 것으로 가접속 시키고 $\mathrm{MAG}$ 에게 접속 요청이 완료되었음을 의미하는 Pre-PBA 메시지를 전송한다. Pre-PBA 메시지를 받은 $\mathrm{MAG}$ 는 더 이상 $\mathrm{PR}$ 로 멀티캐스팅 트래픽을 전송하지 않고 자체적으로 버퍼링을 한다. 그리고 $\mathrm{MAG}$ 는 $\mathrm{MNN}$ 을 $\mathrm{PR}$ 에서

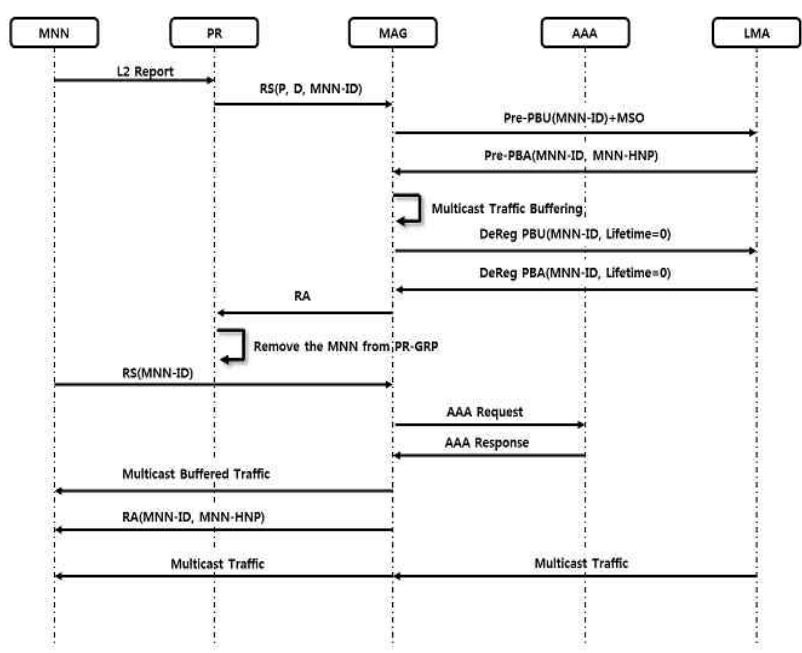

Fig. 8. Node handover operation in the Fast PR- NEMO

접속을 해지시키기 위해 LMA에게 DeReg PBU 메시지를 전송한다. 메시지를 받은 $\mathrm{LMA}$ 는 해당 $\mathrm{PR}$ 그룹에서 $\mathrm{MNN}$ 을 제거하고 가접속되어 있던 $\mathrm{MNN}$ 의 상태를 접속으로 변 경한다. $\mathrm{LMA}$ 는 $\mathrm{MAG}$ 에 DeReg PBA 메시지를 보내 해당 $\mathrm{PR}$ 그룹내에서 $\mathrm{MNN}$ 이 접속 해지 되었음을 알린다. 그 후 $\mathrm{MAG}$ 는 $\mathrm{RA}$ 메시지를 $\mathrm{PR}$ 에 보내 $\mathrm{LMA}$ 캐시에서 $\mathrm{MNN}$ 이 접 속이 해지되었음을 알린다. 메시지를 받은 $\mathrm{PR}$ 은 자체적으로 관리하는 데이터에서 $\mathrm{MNN}$ 의 정보를 삭제한다. $\mathrm{PR}$ 네트워 크에서 벗어난 $\mathrm{MNN}$ 은 $\mathrm{MAG}$ 로 $\mathrm{RS}$ 접속 요청 메시지를 보 내고, $\mathrm{MAG}$ 는 사전 접속을 시켜놓았기 때문에 바로 $\mathrm{AAA}$ 서버에 인증 요청을 한 후 버퍼링되어 있던 멀티캐스팅 트 래픽을 $\mathrm{MNN}$ 에 전송한다. 그리고 $\mathrm{MAG}$ 는 $\mathrm{MNN}$ 에 접속 절 차가 완료되었음을 의미하는 RA 메시지를 전송한다. 이것 으로 $\mathrm{MNN}$ 의 $\mathrm{PR}$ 네트워크에서 $\mathrm{MAG}$ 로 핸드오버하는 절차 가 마무리되고, 그 이후로는 일반적인 PMIPv6의 작동 절차 와 같으며, Fig. 8과 같다.

\section{4. 성능 평가}

이번 장에서는, 기존에 제안된 세가지 방식과 새롭게 제 안하는 방식을 수학적 모델링을 하여 성능평가를 실시한다. 동일 프로토콜 도메인에서의 방식을 다루고, 각 $\mathrm{NEMO}$ 방 식이 얼마나 많이 네트워크에서 생성된 비용을 감소시킬 수 있는지 알아보는 것이기 때문에 비용 분석을 위해 $C_{L U}$ (Cost of the Location Update)와 $C_{P T}$ (Cost of the Packet Tunneling)의 합인 $C_{T O T}$ (Cost of the TOTal)를 분석했다. 각 비용은 메시지의 크기와 대역폭 관점으로 홉 거리에 의 해 정의된다. 이 정의에 따라, 라우터 프로세싱 비용은 고려 하지 않았으며, 분석적인 모델을 위해 아래 사항과 같은 가 정을 했다. $\lambda_{s}$ 의 비율인 세션간 도착 시간은 지수분포를 따 른다. 그리고 패킷에서 평균 세션 길이는 $E(S)$ 이다. MAG 
서브넷 교차 비율은 $\mu_{c}$ 비율의 의미와 일반적인 분포를 따 른다[14]. $d_{\alpha-\beta}$ 는 네트워크 엔티티 $\alpha$ 와 $\beta$ 사이의 홉 거리 를 의미한다. $R S_{\alpha-\beta}$ 와 $R A_{\alpha-\beta}$ 는 $d_{\alpha-\beta}\left(L_{R S}\right)$ 와 $d_{\alpha-\beta}\left(L_{R A}\right)$ 같 이 $\alpha$ 와 $\beta$ 사이의 $\mathrm{RS}$ 와 $\mathrm{RS}$ 메시지 단위 비용을 의미하고, $L_{\gamma}$ 는 각각의 $\gamma$ 의 메시지 크기를 의미한다. 그리고 $L U_{\alpha-\beta}$ 는 $d_{\alpha-\beta}\left(L_{P B U}+L_{P B A}\right)$ 와 같이 $\alpha$ 와 $\beta$ 사이의 $\mathrm{PBU} / \mathrm{PBA}$ 메 시지의 비용을 의미한다.

\section{1 위치 업데이트 비용}

$\mathrm{rNEMO}$ 방식에서는 모바일 네트워크가 다른 MAG로 이 동할 때, $\mathrm{MAG}$ 는 $\mathrm{PR}$ 에서 $\mathrm{MNN}$ 에 보내거나 받는 $\mathrm{PBU} / \mathrm{PBA}$ 메시지에 의한 LMA와 함께 위치 업데이트 동작을 수행한 다. $\mathrm{MNN}$ 은 $\mathrm{RS} / \mathrm{RA}$ 메시지를 $\mathrm{MNN}$ 의 수 만큼 $\mathrm{PR}$ 과 교환 한다. 서브넷 교차의 평균 숫자 중 $\mathrm{T}$ 는 $\mu_{c} T$ 와 같다[14]. 그 러므로 도메인 내의 위치는 rNEMO Intra (1)에 나타난 방 식으로 업데이트 비용이 발생한다. 또한, 도메인 간의 위치 업데이트 비용은 rNEMO Inter (2)와 같으며 도메인 내의 업데이트 비용에 LMA 간 업데이트 비용이 추가 되었다.

$\delta$ 는 $\mathrm{MNN}$ 의 수를 나타내며, $\tau$ 와 $\kappa$ 는 유선/무선 링크 의 단위 전달 비용을 각각 나타낸다. 그리고 일반적으로 무 선 링크의 전달 비용은 유선 링크의 전달 비용 보다 크기
때문에 $\kappa$ 는 $\tau$ 보다 크다고 정의한다.

$\mathrm{N}-\mathrm{PMIPv6}$ 방식에서, mMAG은 $\mathrm{MNN}$ 을 대신하여 업데 이트 작동을 수행한다. $C_{L U}$ 는 $\mathrm{PR}$ 에서 $\mathrm{MNN}$ 의 수에 상관없 이 변하지 않는다. 그러므로 (3)에 의해 상응하는 도메인내 의 $C_{L U}$ 를 계산 할 수 있다. 도메인간의 위치 갱신 비용은 (4)와 같으며, 도메인 내의 위치 업데이트 비용에 LMA간 위치 업데이트 비용이 추가 되었다.

$\mathrm{PR}-\mathrm{NEMO}$ 방식의 제안에서, $\mathrm{PR}$ 또한 $\mathrm{MNN}$ 대신에 위치 업데이트 동작을 수행한다. 그러나 $\mathrm{MNN}-\mathrm{ID}$ 와 $\mathrm{MNN}-\mathrm{HNP}$ 는 $\mathrm{PBA}$ 메시지에 의해 새롭게 접속된 $\mathrm{MAG}$ 에 전달된 $\mathrm{LMA} \mathrm{BCE}$ 에 저장되었다. $\mathrm{MNN}-\mathrm{ID}$ 와 $\mathrm{MNN}-\mathrm{HNP}$ 옵션을 $\mathrm{MNN}$ 의 숫자만큼 추가 하기 위해 $\delta \tau d_{L M A-M A G}\left(L_{M N N-I D}+L_{M N N-H N P}\right)$ 을 $\mathrm{PR}-\mathrm{NEMO}$ 의 $C_{L U}$ 에 각기 추가했다. 따라서 도메인 내의 $C_{L U}$ 는 (5)에 의해 계산될 수 있다. 또한 도메인 간의 $C_{L U}$ 는 (6)에 의해 계산될 수 있으 며, (5)에서 LMA간 위치 업데이트 비용이 추가되었다.

Fast PR-NEMO 방식에서는, 기본적으로 PR-NEMO와 비슷한 절차로 위치 업데이트를 수행하기 때문에 $\mathrm{PR}-\mathrm{NEMO}$ 와 기본 계산법은 유사 하지만, 가 접속을 하여 핸드오버를 진행하기 때문에 추가적으로 $\mathrm{pMAG}$ 에서 $\mathrm{nMAG}$ 로 핸드오버 준비 신호를 유선으로 보내는 $\tau H I$ 와 $\tau H A$ 값 이 추가 되었다. 따라서 도메인 내의 $C_{L U}$ 는 (7)에 의해 계

$$
\begin{aligned}
& C_{L U-\text { Intra }}^{r N E M O}=\mu_{c} T \delta\left(\kappa R S_{M N N-M A G}+\kappa R A_{M A G-M N N}+2 \tau A A A_{M A G-A A A}+2 \tau L U_{M A G-L M A}\right) \\
& C_{L U-I n t e r}^{r N E M O}=\mu_{c} T \delta\left(\kappa R S_{M N N-M A G}+\kappa R A_{M A G-M N N}+2 \tau A A A_{M A G-A A A}+2 \tau L U_{M A G-L M A}\right)+ \\
& 2 \mu_{c} T \delta \times d_{L M A 1-L M A 2}\left(L_{P-Q u e r y}+L_{P-A c k}\right) \\
& C_{L U-I n t r a}^{N-P M I P 6}=\mu_{c} T\left(\kappa R S_{m M A G-M A G}+\kappa R A_{M A G-m M A G}+2 \tau A A A_{M A G-A A A}+2 \tau L U_{M A G-L M A}\right) \\
& C_{L U-\text { Inter }}^{N-P \text { PIP }}=\mu_{c} T\left(\kappa R S_{\text {mMAG-MAG }}+\kappa R A_{M A G-m M A G}+2 \tau A A A_{M A G-A A A}+2 \tau L U_{M A G-L M A}\right)+ \\
& 2 \mu_{c} T \times d_{L M A 1-L M A 2}\left(L_{P-Q u e r y}+L_{P-A c k}\right) \\
& C_{L U-I n t r a}^{P R-N E M O}=\mu_{c} T\left(\kappa R S_{P R-M A G}+\kappa R A_{M A G-P R}+2 \tau A A A_{M A G-A A A}+2 \tau L U_{M A G-L M A}+\right. \\
& \left.\delta \tau d_{L M A-M A G}\left(L_{M N N-I D}+L_{M N N-H N P}\right)\right) \\
& C_{L U-\text { Inter }}^{P R-N E O}=\mu_{c} T\left(\kappa R S_{P R-M A G}+\kappa R A_{M A G-P R}+2 \tau A A A_{M A G-A A A}+2 \tau L U_{M A G-L M A}+\right. \\
& \left.\delta \tau d_{L M A-M A G}\left(L_{M N N-I D}+L_{M N N-H N P}\right)\right)+ \\
& 2 \mu_{c} T \times d_{L M A 1-L M A 2}\left(L_{P-\text { Query }}+L_{P-A c k}\right) \\
& C_{L U-\text { Intra }}^{\text {FastP-NEMO }}=\mu_{c} T\left(\kappa\left(R S_{P R-n M A G}+R A_{n M A G-P R}\right)+2 \tau A A A_{n M A G-A A A}+2 \tau L U_{n M A G-L M A}+\right. \\
& \left.\delta \tau d_{L M A-n M A G}\left(L_{M N N-I D}+L_{M N N-H N P}\right)+\tau\left(H I_{p M A G-n M A G}+H A_{n M A G-p M A G}\right)\right) \\
& C_{L U-\text { Inter }}^{\text {FastP-NEMO }}=\mu_{c} T\left(\kappa\left(R S_{P R-n M A G(L M A 2)}+R A_{n M A G(L M A 2)-P R}\right)+\right. \\
& 2 \tau A A A_{n M A G(L M A 2)-A A A}+2 \tau L U_{n M A G(L M A 2)-L M A 2}+ \\
& \delta \tau d_{L M A 2-n M A G(L M A 2)}\left(L_{M N N-I D}+L_{M N N-H N P}\right)+ \\
& \left.\tau\left(H_{p M A G(L M A 1)-n M A G(L M A 2)}+H A_{n M A G(L M A 2)-p M A G(L M A 1)}\right)\right)
\end{aligned}
$$




$$
\begin{aligned}
C_{P T-\text { Intra }}^{r N E M O} & =\lambda_{s} T E(S)\left(\tau d_{L M A-M A G} L_{T}\right) \\
C_{P T-\text { Inter }}^{r N E M O} & =\lambda_{s} T E(S)\left(\tau d_{L M A-M A G} L_{T}+\tau d_{L M A 1-L M A 2} L_{P}\right) \\
C_{P T-\text { Intra }}^{N-P M I P v 6} & =\lambda_{s} T E(S)\left(\tau d_{L M A-M A G} 2 L_{T}+\kappa d_{M A G-m M A G} L_{P}\right) \\
C_{P T}^{N-P M I P \nu 6} & =\lambda_{s} T E(S)\left(\tau d_{L M A 2-M A G(L M A 2)} 2 L_{T}+\kappa d_{n M A G(L M A 2)-m M A G} L_{P}+\right. \\
& \left.\tau d_{L M A 1-L M A 2} L_{P}\right)
\end{aligned}
$$

산될 수 있다. 도메인간 위치 업데이트 비용은 (7)에서 $\mathrm{MAG}$ 가 직접 메시지를 주고 받기 때문에 (8)과 같이 계산 될 수 있다.

\section{2 패킷 터널링 비용}

패킷 터널링 비용은 $\mathrm{CN}$ 에서 $\mathrm{MNN}$ 으로부터 유래된 데이 터 패킷의 IP 터널 헤더 크기를 의미한다. 패킷의 값은 Little's law[15]에서 유래되었다. T는 $\lambda_{s} T E(S)$ 에 의한 대략 적인 값이다. 그러므로 $\mathrm{rNEMO}$ 의 도메인 내의 $C_{P T}$ 는 (9)에 의해 나타낼 수 있고, 도메인간 패킷 터널링 비용은 도메인 간 터널링 비용이 추가되어 (10)에 의해 계산될 수 있다.

$\mathrm{N}-\mathrm{PMIPv6}$ 에서, LMA가 $\mathrm{MNN}$ 주소로 설명된 패킷을 받 을 때, 패킷은 두 터널 해더를 받은 패킷에 추가하여 $\mathrm{MAG}$ 에 보내진다. MAG는 단지 외부 헤더를 제거하고 나머지를 $\mathrm{mMAG}$ 로 보낸다. 그러므로 N-PMIPv6의 도메인 내의 $C_{P T}$ 를 (11)과 같이 나타낼 수 있고, 도메인간 패킷 터널링 비용 은 (11)에 도메인간 터널링 비용이 추가되어 (12)에 의해 나 타낼 수 있다.

MAG와 LMA 사이에서 사용되는 PMIPv6 터널 해더를 제외하면 사용되는 터널 해더는 없기 때문에 PR-NEMO의 도메인 내의 $C_{P T}$ 는 $\mathrm{rNEMO}$ 의 도메인 내 $C_{P T}$ 와 같으므로 (13)과 같이 나타낼 수 있고, (14)에 의해 도메인간 $\mathrm{PR}-\mathrm{NEMO}$ 의 패킷 터널링 비용을 계산할 수 있다.

$$
\begin{aligned}
& C_{P T-\text { Intra }}^{P R-N E M O}=\lambda_{s} T E(S)\left(\tau d_{L M A-M A G} L_{T}\right) \\
& C_{P T-\text { Inter }}^{P R-N E M O}=\lambda_{s} T E(S)\left(\tau d_{L M A 2-n M A G(L M A 2)} L_{T}+\tau d_{L M A 1-L M A 2} L_{P}\right)
\end{aligned}
$$

Fast PR-NEMO 는 MAG가 직접 터널링을 하기 때문에 도메인간 패킷 터널링 비용은 (15)와 같이 계산되어 질 수 있고, (16)에 의해 도메인간 패킷 터널링 비용을 계산할 수 있다.

$$
\begin{aligned}
C_{P T-\text { Intra }}^{\text {FastPR-NEMO }} & =\lambda_{s} T E(S)\left(\tau d_{p M A G-n M A G} L_{T}\right) \\
C_{P T-\text { Inter }}^{\text {FastPR-NEMO }} & =\lambda_{s} T E(S)\left(\tau d_{p M A G(L M A 1)-n M A G(L M A 2)} L_{T}\right)
\end{aligned}
$$

\section{3 수치분석 결과}

rNEMO, N-PMIPv6, PR-NEMO, Fast PR-NEMO의 네 가지 기법에 대한 전체 비용을 계산하기 위해 사용된 매개 변수 값[16]이 Table 1에 있다.

Fig. 9는 세션 도착 비율에 대한 총 비용을 보여준다. 세션 도착 비율이 점차 증가하면서 패킷 전달 비용도 기법들간 차 이가 많이 발생했다. 특히 $\mathrm{N}-\mathrm{PMIPv} 6(\mathrm{E}(\mathrm{S})=30)$ 기법의 총 비 용이 눈에 띄게 증가했다. $\mathrm{rNEMO}$ 가 $\mathrm{PR}-\mathrm{NEMO}$ 와 같은 패킷 터널링 비용을 가지지만, 총 비용은 $\mathrm{rNEMO}$ 가 PR-NEMO보 다 크게 나왔다. $\mathrm{rNEMO}$ 작동방법이 각각의 $\mathrm{MNN}$ 의 수 만큼 위치 업데이트를 하도록 설계되어 있기 때문에 $\mathrm{rNEMO}$ 가 Fast-NEMO, PR-NEMO보다 큰 값이 나오게 된다.

Fig. 10은 rNEMO가 빈번한 핸드오프에 매우 취약하다는 것을 보여준다. N-PMIPv6와 $\mathrm{PR}-\mathrm{NEMO}$ 의 총 비용 또한 증가했다, 그러나 $\mathrm{PR}$ 의 핸드오버 시그널링으로 부터 증가하 는 결과가 나왔다.

Fig. 11 은 $\mathrm{MNN}$ 의 수에 따른 총 비용의 결과를 보여준다. $\mathrm{MNN}$ 수가 증가할수록 $\mathrm{rNEMO}$ 의 총 비용이 다른 기법들 에 비해 급격하게 증가하는 것을 나타내고 있다. 왜냐하면 패킷 터널링 비용이 급격히 증가하기 때문이다. Fast $\mathrm{PR}-\mathrm{NEMO}$ 기법에서는 $\mathrm{MNN}$ 의 수 만큼 $\mathrm{PBA}$ 메시지 크기 도 증가했다. 그리고 증가하는 $\mathrm{MNN}$ 에 대한 패킷 터널링 비용 또한 같은 시간에 약간 증가하였다. $\mathrm{E}(\mathrm{S})$ 를 $\mathrm{MNN}$ 당 적어도 10 패킷으로 추정하면, 결과는 증가된 $\mathrm{PBA}$ 크기가 총 비용에 많은 영향을 미치지 않았다는 것을 보여준다.

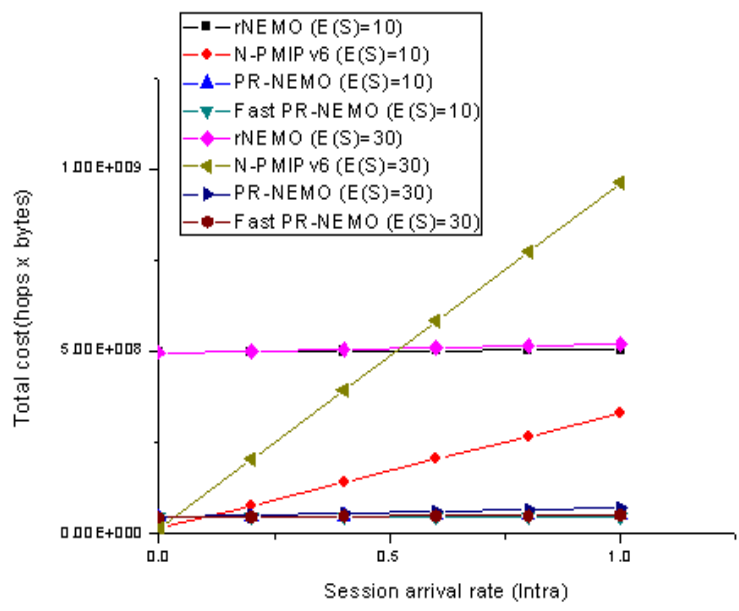

Fig. 9. Total cost for the session arrival rate, Intra 
Table 1. Parameter values for performance analysis

\begin{tabular}{cccc}
\hline 매개변수 & 값 & 매개변수 & 값 \\
\hline$d_{M N N-P R(m M A G)}$ & 1 & $\delta$ & 10 \\
$d_{P R(m M A G)-M A G}$ & 1 & $\kappa$ & 0.5 \\
$d_{M A G-A A A}$ & 1 & $\tau$ & 1000 \\
$d_{M A G-L M A}$ & 4 & $\mathrm{~T}$ & 1000 \\
$\mathrm{RS}$ & 70 & $\mathrm{~S}$ & 112 \\
$\mathrm{RA}$ & 110 & $\mathrm{PBU}$ & 96 \\
$\mathrm{AAA}$ & 100 & $\mathrm{PBA}$ & 1500 \\
$L_{T}$ & 40 & $L_{p}$ & 10 \\
$\mathrm{HI}$ & 32 & $\mathrm{HA}$ & 50 \\
$L_{P-Q u e r y}$ & 100 & $L_{P-A c k}$ & \\
\hline
\end{tabular}

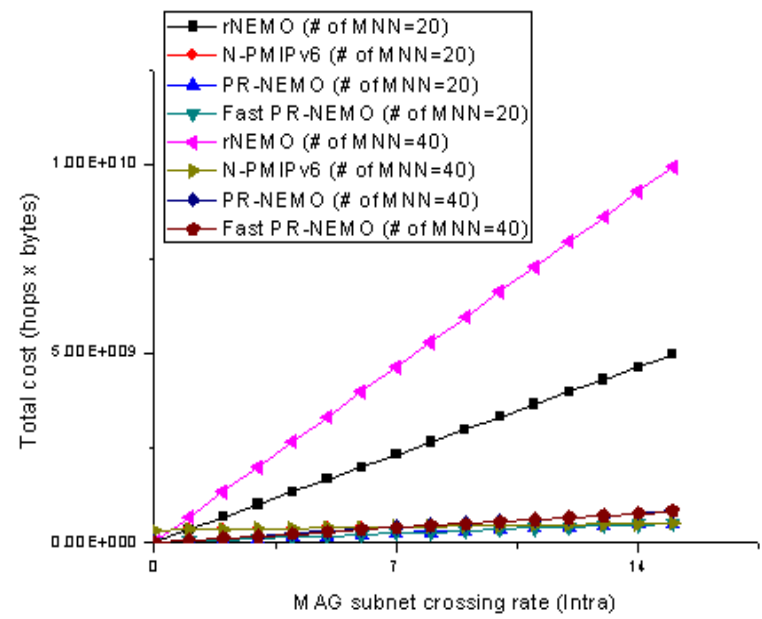

Fig. 10. The MAG subnet crossing rate, Intra

$\mathrm{MNN}$ 수 만큼 더 많은 데이터를 가지고 있어도 다른 대상 과 비교하여도 가장 작은 총 비용을 발생 시키는 것을 확인 할 수 있다.

$\mathrm{PR}-\mathrm{NEMO}$ 와 $\mathrm{rNEMO}$ 의 총 비용을 비교할 때, 결과는 또 한 $\mathrm{PR}-\mathrm{NEMO}$ 의 증가된 $\mathrm{PBA}$ 크기가 증가하는 위치 업데이 트 비용보다 작다고 보여준다. 다양한 네트워크 환경의 총 비용을 보여주기 위해, 세션 도착 비율을 핸드오프 비율로 나눈 $\operatorname{SMR}$ (Session to Mobility Ratio)을 사용한다. SMR이 크면, 세션 활동성이 핸드오프 비율보다 비교적 높다는 것 을 의미한다. Fig. 12, 13에서 Fast PR-NEMO는 SMR의 증 가에 따라 변동이 거의 없고 다른 기법에 비해 가장 낮은 총 비용을 발생시키는 것을 확인할 수 있다.

도메인간의 핸드오버 절차에 대한 성능분석은 도메인 내

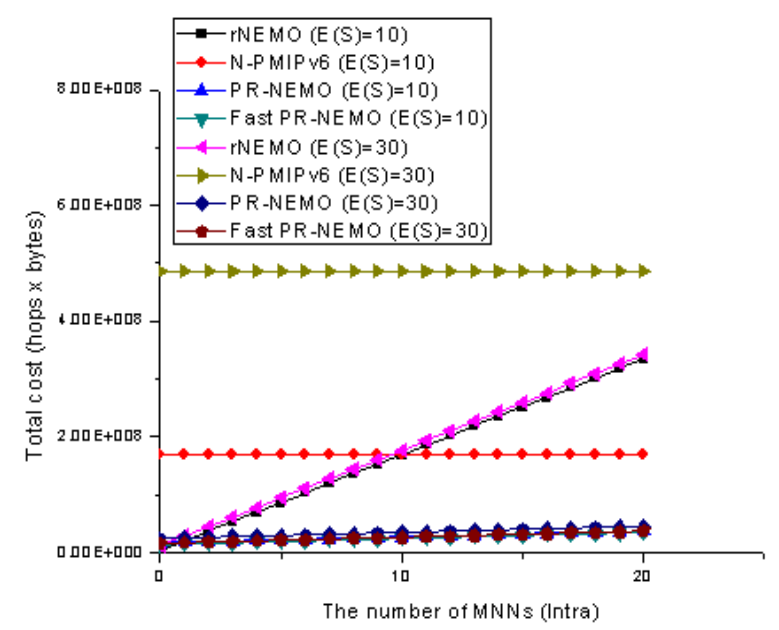

Fig. 11. Total cost as the number of MNNs, Intra

의 평가 방법에 LMA 간 발생하는 추가적인 비용이 더 해진 것이며, 세션 도착 비율에 따른 총 비용을 살펴보면 Fig. 14 와 같은 결과를 얻을 수 있다. 다른 기법들은 세션 도착 비 율이 증가 함에 따라 급격히 비용이 증가하는 것을 살펴볼 수가 있지만, Fast PR-NEMO 기법은 비율의 변동에 상관없 이 가장 낮게 일정한 값을 유지하고 있는 것을 알 수 있다.

도메인간 서브넷 교차 비율에 따른 총 비용은 $\mathrm{rNEMO}$ 기법이 다른 기법과 비교 했을 때 가장 급격한 변화를 일으 키는 것을 Fig. 15에서 확인할 수 있고, 또한 Fast PR$\mathrm{NEMO}$ 가 $\mathrm{PR}-\mathrm{NEMO}$ 에 비교해서 낮은 값을 유지하면서 서 서히 증가 하는 것을 확인할 수 있다.

도메인간 $\mathrm{MNN}$ 의 수에 따른 총 비용에 대한 성능 분석 결과는 Fig. 16 과 같으며, 다른 기법들은 $\mathrm{MNN}$ 의 수에 상관 


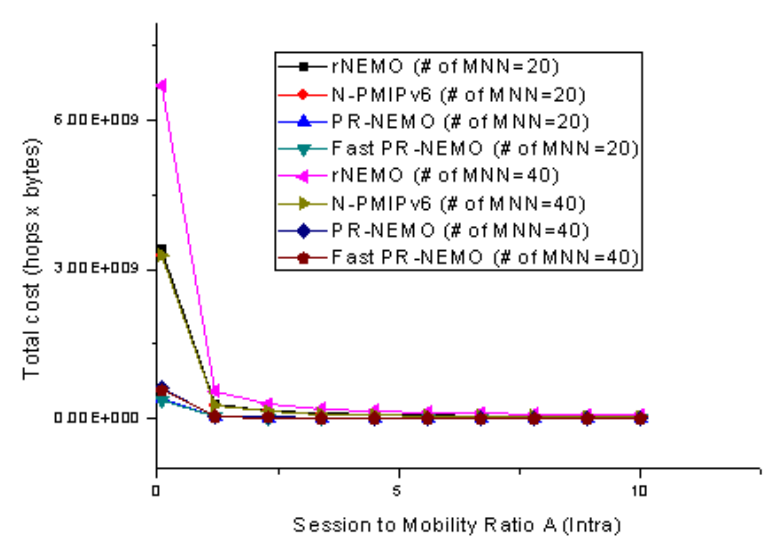

Fig. 12. Total cost as SMR A, Intra

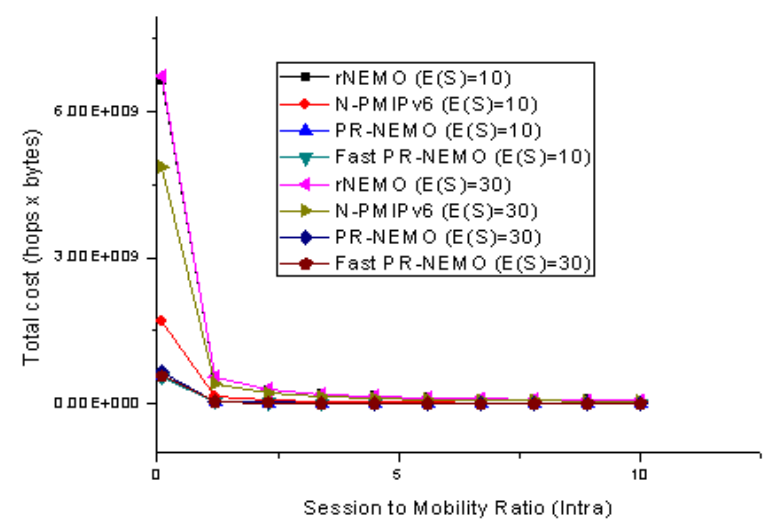

Fig. 13. Total cost as SMR B, Intra

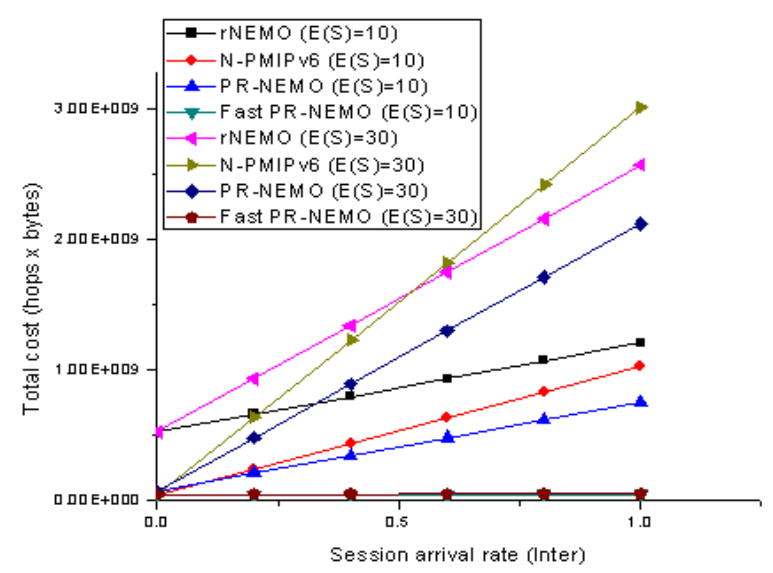

Fig. 14. Total cost for the session arrival rate, Inter

없이 일정한 비용을 발생시키는 것을 확인할 수 있으나, $\mathrm{rNEMO}$ 기법은 $\mathrm{MNN}$ 의 수가 증가하면서 비용 또한 증가하 고 있는 것을 확인할 수 있다. Fast PR-NEMO 기법은 비 교 대상들 중 가장 낮은 비용을 발생 시키며 $\mathrm{MNN}$ 의 증가 에 가장 효율적인 방법인 것으로 확인할 수 있다.

$\mathrm{NEMO}$ 기법들의 도메인간 총 비용을 비교할 때, 결과는 또한 Fast PR-NEMO의 증가된 $\mathrm{PBA}$ 크기가 증가하는 위치

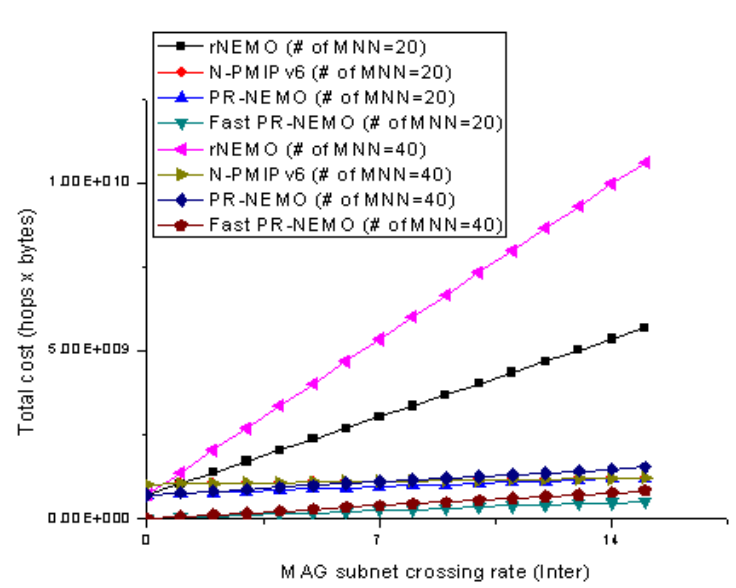

Fig. 15. The MAG subnet crossing rate, Inter)

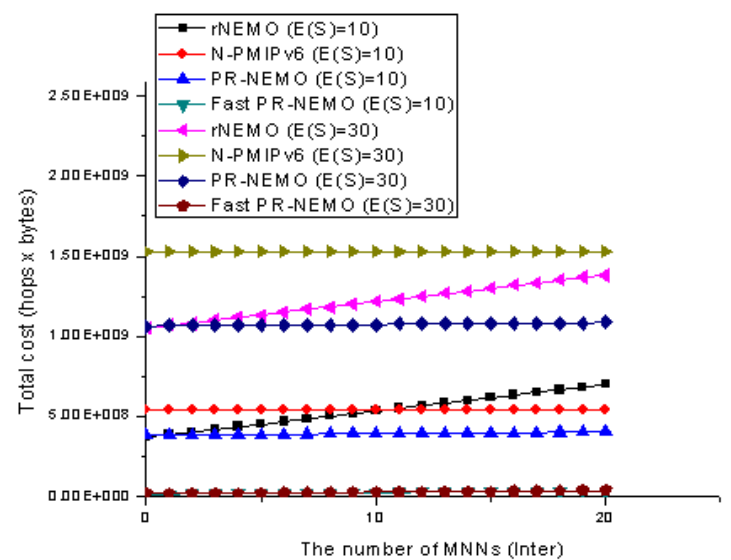

Fig. 16. Total cost as the number of MNNs, Inter

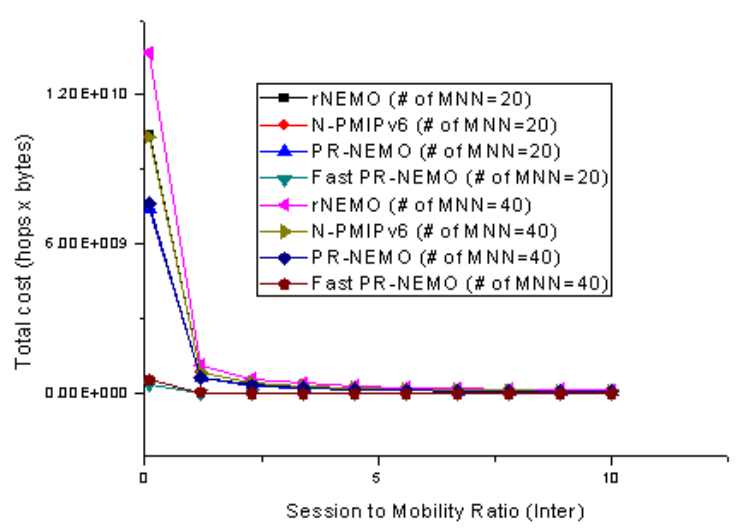

Fig. 17. Total cost as SMR A, Inter

업데이트 비용보다 작다고 보여준다. 다양한 네트워크 환경 의 총 비용을 보여주기 위해, 세션 도착 비율을 핸드오프 비율로 나눈 SMR을 사용한다. SMR이 크면, 도메인간 세션 활동성이 핸드오프 비율보다 비교적 높다는 것을 의미한다. Fig. 17, 18에서 Fast PR-NEMO는 SMR의 증가에 따라 거 의 변동이 없고 $\mathrm{rNEMO}$ 가 가장 많은 비용이 발생하고 N-PMIPv6 기법이 다음으로 높은 비용을 발생 시키며 


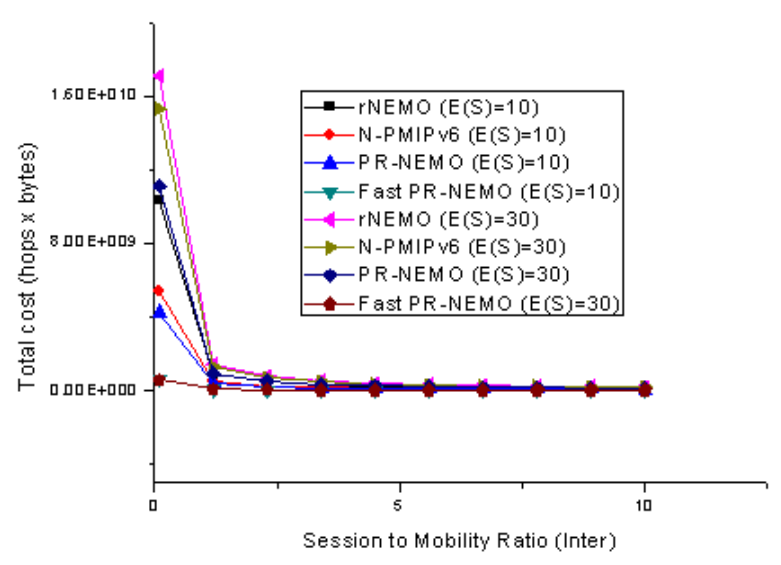

Fig. 18. Total cost as SMR B, Inter

$\mathrm{PR}-\mathrm{NEMO}$ 가 기존 기법 중에서는 가장 낮은 비용을 발생 시키고 Fast PR-NEMO 기법이 가장 낮은 총 비용을 발생 시키는 것을 확인할 수 있다.

\section{5. 결 론}

본 논문에서는 PMIPv6 네트워크를 통한 Fast PR$\mathrm{NEMO}$ 라고 불리는 비용 효율적인 $\mathrm{NEMO}$ 프로토콜을 제안 했다. Fast PR-NEMO는 효율적인 이동성관리와 패킷 전송 메소드를 제공하며, 멀티캐스팅 지원, 고속 핸드오버, 도메인 간 핸드오버를 지원한다. 결과적으로, Fast PR-NEMO는 위 치 업데이트 오버헤드와 패킷 터널링 오버헤드를 감소시켰 다. Fast PR-NEMO, PR-NEMO, N-PMIPv6, rNEMO의 총 비용을 분석과 평가하여, Fast PR-NEMO가 다른 방법들과 비교하여 핸드오버 시 가장 우수한 비용 효율성을 가지는 것을 증명하였으며, 데이터 손실이 적고, 지연시간이 거의 없으며 도메인간의 핸드오버도 지원하는 NEMO 솔루션이라 는 것을 확인했다. 기존의 기법들의 문제점을 개선하여 상 대적으로 저비용으로 보다 높은 만족도를 가질 수 있으며, 이는 Fast $\mathrm{PR}-\mathrm{NEMO}$ 가 이동성 $\mathrm{Wi}-\mathrm{Fi}$ 환경에 가장 적합한 솔루션으로 판단할 수 있는 근거가 된다. 또한 추가적인 연 구를 통해 고려되지 않았던 기존의 다른 기법들과의 성능 분석을 수행을 할 계획이다.

\section{참 고 문 헌}

[1] Pack S., Shen X., Mark J.W. and Pan J., "Mobility management in mobile hotspots with heterogeneous multihop wireless links," IEEE Commun. Mag., 45, 9, pp.106-112, September, 2007.

[2] Devarapalli V., Wakikawa R., Petrescu A. and Thubert, P., "Network mobility (NEMO) basic support protocol," IETF RFC 3963, January, 2005.

[3] Johnson, D. Perkins and C. Arkko, J., "Mobility support in IPv6," IETF RFC 3775, June, 2004.
[4] Zabin F., Misra S., Woungang I., Rashvand H.F., Ma N.-W. and M. Ahsan Ali, "REEP: data-centric, energy-efficient and reliable routing protocol for wireless sensor networks," IET Commun., 2, 8, pp.995-1008, April, 2007.

[5] Venkataraman G., Emmanuel S. and Thambipillai, S., "Energy-efficient cluster-based scheme for failure management in sensor networks," IET Commun., 2, 4, pp.528-537, April, 2008.

[6] Namboodiri V. and Gao L., "Energy-efficient VoIP over wireless LANs," IEEE Trans. Mob. Comput., 9, 4, pp.566-581, April, 2010.

[7] Lee J., Ernst T. and Chung T., "Cost analysis of IP mobility management protocols for consumer mobile devices," IEEE Trans. Consum. Electron., 56, 2, pp.1010-1017, May, 2010.

[8] Makaya C. and Pierre S., "An analytical framework for performance evaluation of IPv6-based mobility management protocols," IEEE Trans. Wirel. Commun., 7, 3, pp.972-983, March, 2008.

[9] Gundavelli S., Leung K., Devarapalli V., Chowdhury K. and Patil B., "Proxy mobile IPv6," IETF RFC 5213, August, 2008.

[10] Soto I., Bernardos C.J., Calderon M., Banchs A. and Azcorra A., "NEMO-enabled localized mobility support for internet access in automotive scenarios," IEEE Commun. Mag., 47, 5, pp.152-159, May, 2009.

[11] Pack S., "Relay-based network mobility support in proxy mobile IPv6 networks," Proc. IEEE CCNC 2008, pp.227-228, January, 2008.

[12] Abinader F., Gundavelli S., Leung K., Krishnan S. and Premec D., "Bulk re-registration for proxy mobile IPv6," draftietf-netext-bulk-reregistration-01.txt, January, 2010.

[13] Aboba B., Beadles M., Arkko J. and Eronen P., "The network access identifier," RFC 4282, December, 2005.

[14] Pack S., Shen X., Mark J.W. and Pan J., "Adaptive route optimization in hierarchical mobile IPv6 networks," IEEE Trans Mob. Comput., 6, 8, pp.903-914, August, 2007.

[15] Kleinrock L., "Queueing systems volume 1: theory," John Wiley \& Sons, January, 1975.

[16] Jeon S., Kang N. and Kim Y., "Enhanced predictive handover for fast proxy mobile IPv6," IEICE Trans Commun., E92-B, 11, pp.3504-3507, November, 2009.

[17] Jeon S. and Kim Y., "Cost-efficient network mobility scheme over proxy mobile IPv6 network," Communications, IET, 5, 18, pp.2656-2661, December, 2011.

[18] Seung-Hyun Lee, Dong-Ryeol Shin, Jongpil Jeong, "SePH: Seamless Proxy-based Handoff Scheme in IP-Based 
Heterogeneous Mobile Networks," The KIPS Transactions : Part C, 19, 1, pp.71-82, 2012

[19] Chai Hyun Suk, Jeong Jong Pil, "Security Analysis and Implementation of Fast Inter-LMA domain Handover Scheme in Proxy Mobile IPv6 Networks," The KIPS Transactions : Part C, 19, 2, pp.99-118, 2012.

[20] Sewon Yoo, Jongpil Jeong, "Analytical Approach of Fast Inter-Domain Handover Scheme in Proxy Mobile IPv6 Networks with Multicasting Support," The KIPS Transactions : Part C, 19, 2, pp.153-166, 2012.

[21] Jae-Hoon Kim, Jongpil Jeong, "Performance Analysis of Cost-Effective Handoff Scheme in PMIPv6 Networks with DNS Supporting," The Institute of Webcasting, Internet And Telecommunication, 11, 4, pp.131-140, August, 2011.

[22] Do-Kyoung Ra, Jongpil Jeong, "Cost-Effective Mobility Management Scheme in Proxy Mobile IPv6 Networks with Function Distributor Support," The Institute of Webcasting, Internet And Telecommunication, 12, 1, pp.97-107, February, 2012.

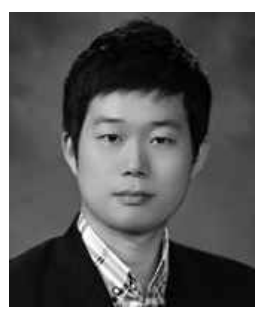

한 성 희

e-mail : iwas1006@gmail.com 2010년 중앙대학교 정보시스템 학사 2012년 현 재 성균관대학교 정보통신대학원 석사과정 관심분야: 모바일컴퓨팅, 네트워크 보안, IT 융합 등

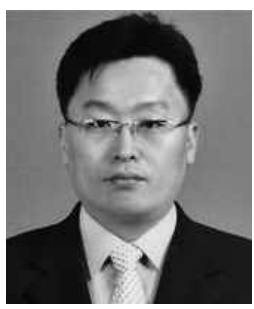

\section{정 종 필}

e-mail : jpjeong@skku.edu

2008년 성균관대학교 정보통신대학 (공학박사)

2009년 성균관대학교 컨버전스연구소 연구교수

2010년 현 재 성균관대학교 산학협력단 산학협력중점교수

관심분야: 모바일 컴퓨팅, 센서 이동성, 차량 모바일 네트워크, 스마트기기 보안, 네트워크 보안, IT 융합, 인터랙션 사이언스 등 